\title{
Concept Analysis: Engagement in Personal HIV Management
}

\author{
Matt L. Pimentel \\ School of Nursing and Health Studies, University of Missouri-Kansas City, Kansas City, USA \\ Email: matt_pim2004@yahoo.com
}

Received 21 May 2015; accepted 5 June 2015; published 12 June 2015

Copyright (C) 2015 by author and OALib.

This work is licensed under the Creative Commons Attribution International License (CC BY). http://creativecommons.org/licenses/by/4.0/

(c) (i) Open Access

\begin{abstract}
A concept analysis is an endeavor in social sciences to ensure proper usage of the term among researchers, theorists, and practitioners. The concept of engagement has recently been touted as the term describing HIV-infected individuals who are compliant with their highly active antiretroviral therapy (HAART) medications. Accordingly, engagement has also come to mean that the full compliance with not just HAART, but also compliance with lab tests, medical visits, and counseling services. Post-release incarcerated male inmates that are HIV-infected (IMIHIV) are an especially vulnerable population in regard to access to care and compliance with HAART medications and services. Therefore, full understanding of the meaning and context of the term engagement is imperative to begin a conversation about these individuals. Thus, engagement in personal HIV management will be stressed.
\end{abstract}

\section{Keywords}

HIV, Engagement, Inmates, Inmate Health, HAART, Concept Analysis

Subject Areas: HIV, Immunology

\section{Introduction}

This concept analysis will be discussing the term engagement in personal HIV management. This engagement has a very narrow focus that includes engaging in taking highly active antiretroviral therapy (HAART) and adherence with medical appointments. The purpose of this concept analysis is to fully understand the meaning of this phrase and its new context in HIV care. The secondary goal is to have this engagement compliance with all incarcerated male inmates who are HIV-infected (IMIHIV). Keeping all post-release IMIHIV engaged in all aspects of the HIV care and the HIV-infected paradigm is paramount for a healthy society and to remedy pain and suffering.

IMIHIV is an underserved, vulnerable population in the United States. There is a paucity of studies that spe- 
cifically address issues relating to IMIHIV and how healthcare measures may be able to prevent untoward healthcare outcomes. Moreover, when IMIHIV's issues are addressed, it reveals high rates of recidivisms, high rates of mental health issues, high risk of sexual behaviors, and low rates of engagement with the most prominent HIV therapy, which is HAART [1]-[3]. The significance is that 135,000 men are released into society each year, with approximately $1.5 \%$ of them being HIV-infected, many of which have a tendency to not sustain HAART therapy [4].

Engagement is the process in which individuals who are HIV-infected remain compliant with their administration of the HAART regimen [5]. Keeping a person that is HIV-infected engaged in HAART keeps the viral level low to undetectable levels [6], and halts the spread of HIV from person to person and to the community about $96 \%$ of the time [7]. Incarcerated populations' propensity toward engagement is low as shown by the relatively few studies in which the 30-day compliance after release is between $18 \%$ - 23\% and no higher than 30\% for 60 day refills [3].

\section{Method of Analysis}

The methodology used will be Walker \& Avant's simplified view of the Wilsonion method that focuses on eight steps instead of eleven. As concept analysis "is the process of examining the basic elements of a concept [8], pg. 158. The eight steps are to select the concept, determine the aims and purposes of the analysis, identify all uses of the concept, determine the defining attributes, construct a model case, construct a borderline, contrary, and related case, identify antecedents and consequences, and define empirical referents [8]. Being able to extract a clear and concise definition on what engagement is and what it is not is imperative. For this endeavor, the following search engines were used: Medline, PubMed, Proquest, Sociologic, EBSCO Psychology, and Behavior health, EBSCO Education Full Text, and Academic Search Complete.

After an exhaustive search and narrowing the criteria of "engagement," mutually with "HIV infection," 353 results were accrued. Of those, 53 met the criteria of referring to engagement in the sense of the HIV-infected person, the overall community, or with the provider. Further narrowing to 14, led to the most relevant and germane references to the term engagement.

\section{Definition of Engagement}

The term engagement has a convoluted path to current definition; interestingly it has many idiosyncratic meanings, though these meanings have a similar underlining essence of being "in something," whether figuratively or literally. The history of the word is from the 1550's from the Latin stipulari to "exact a promise." In the 1600's, the meaning was a "formal promise," to a "battle" or "fight." The inference to marriage came about in 1742, while the premise of an "appointment," came around 1806. Per the Merriam-Webster dictionary (2012):

1) An arrangement to meet or be present at a specified time and place.

2) A job or period of employment especially as a performer.

3) Emotional involvement or commitment.

4) A pledge or obligation.

5) Betrothal (engagement to get married).

6) The state of being in gear.

7) A hostile encounter between military forces.

The definition of engagement seems to also have a connotation of being not just "in something," but it needs two things (or more) to be complete. As in a war, you need two parties; at least, the "state of being in gear," requires a gear stick and gear wheel, or again, two items. Emotional involvement needs two persons, or one person and another item of desire. Moreover, an arrangement to meet requires one person and at least another item of involvement.

\section{Review of the Literature}

The Outreach Initiative funded by the Health Resources and Services Administration in 2001 determined, that it was imperative to engage people in HIV care, turn sporadic users of care into regular users, and promote retention in care [9]. This was the first mention of the term engagement in the context of HIV care or dealing with individuals that are HIV-infected. In 2005, the Department of Health and Human Services considered engagement 
in the context of HIV, to be the full amalgamation of case management, medical care, mental health, oral health, substance abuse outpatient and residential care, home health care, rehabilitation services, food services, client advocacy, health education/risk reduction, transportation services, treatment adherence counseling, psychosocial support services, emergency financial assistance, nutrition services, outreach services and companion services $[10]$.

Up until this time, though engagement was inferred, the aspect of the HIV-infection paradigm focused either on medication compliance or adherence to medical visits. It was not inferred to be at least both of these two aspects until 2006. An intriguing study of Hispanic individuals showed through structured equation modeling, a high degree of engagement if the parent of the patient and the provider had a conducive relationship [11]. In this sense, it was mentioned that engagement included both medication and medical involvement. Initially, it was research that stipulated the term, engagement, without ambiguity [11].

Social support from a series of ancillary sources, providers, nurses, and peer support, are crucial for hard-toreach clientele to stay engaged in current HIV treatments [12]. If a client had nine contacts or more (social supports) from medical or ancillary sources, there was a substantial reduction in non-compliance for primary care visits in a 12-month time frame [13]. One year follow up studies showing baseline engagement at certain levels, showed $60 \%$ full engagement by years end by stipulating discontinued drug use, decreased unmet needs, and structural barriers were significantly associated with engagement in care [14]. This display of coping was tantamount to success if the factors of drug use, unmet needs, structural barriers, and belief barriers were met [15].

Others used a five-type dichotomous scale level of engagement by measuring if patients visited not just medical services, but also ancillary services such as dentist, case management, treatment education and substance abuse treatment [16]. Social supports are crucial to this population of interest.

Per the Health Resources and Services Administration, there are denominators or measures of engagement in care. Engagement in continuous care comprised of two or more physician visits three or months apart per year [17]. Maintaining contact with social workers and primary care physicians to preclude a concise definition of engagement in her study of young Hispanic and African American men who have sex with men [18]. The most overt descriptor is one researcher who describe the cascade beyond adherence to HAART and compliance to clinical visits; this jointly is openly stated as engagement in HIV care [19]. The author goes further in discussing a trifecta approach of engagement that entails linkage, retention, and re-engagement [19]. Stepping back one year, he stated that engagement was the linkage and retention of care and its interrelatedness.

Failure to engage with the procedure paradigm will render poorer health outcomes for individual that are HIV-infected and the overall community [20]. Specifically, viralogic failure, delayed HAART initiation, and mortality. HIV Medicine Association's current guidelines discussed adherence to care of the individuals rather than focusing on medication compliance [21]. Barriers to engagement are being HIV diagnosis acceptance, coping with stigma, mental health issues, substance usage, poor health care provider relationships, poor external support systems, and navigating outside practical barriers to care [15]. Though rarely touched upon in the literature, these factors are personalized hindrances to engagement. True, there are physical and exterior hindrances to engagement, but actual psychological descriptions of intent are scarce. Attitude, beliefs, emotions, denial, lack of self-assessment, lack of self-positive reinforcement was deemed overwhelmingly the most important when it came to lack of engagement in HAART and physician follow-up [22].

Measurement of linkage of care is quite dichotomous, though measuring retention in care is quite another. Researchers had posited five potential ways on measuring engagement vis-à-vis physician visits rather than the linkage component [23]. They are: missed visits (visits missed per quarter), appointment adherence (proportion of seen visits versus scheduled), visit consistency (time intervals between visits), gaps in care, and a Clinic Visit Measurement Performance (quantitative, administrative tracking tool). (This will be discussed in Empirical Referents). Heretofore, retention measures were commonly ascertained by total visits to any healthcare practitioner in a 30,60, or 90 day period [16]. HIV care engagement to encompass self-care which includes access to care and also, critically, active self-involvement in care by the patient [24].

Currently, the US National HIV/AIDS Strategy stipulates approaches to HIV prevention include that individuals that are HIV-infected be diagnosed as soon as possible after they acquire HIV [25]. Additionally, these individuals should become linked to medical care and to be on HAART in concert with national guidelines.

Figure 1 provides an excellent and current description of engagement in our current society. Although it is not considered ubiquitous in the literature, it is the most relevant, cogent, and descriptive visual that could be ascertained. The figure denotes a six-option statement that would pertain to an individual. As you can see, 


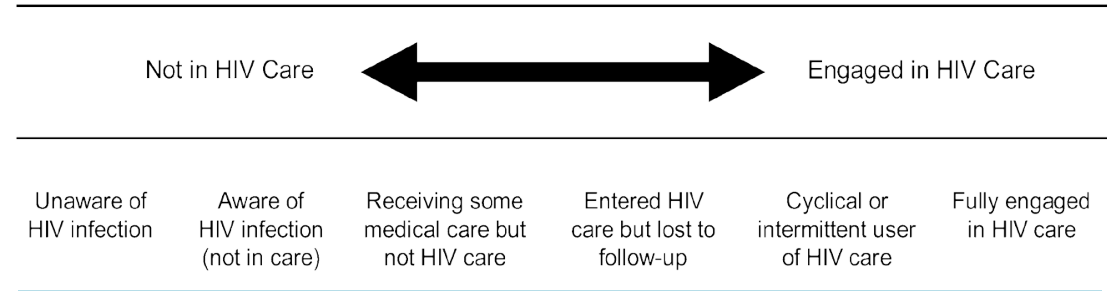

Figure 1. Health Resources and Services Administration (HRSA) continuum of HIV care, describing the spectrum of engagement in HIV care (Elred \& Malitz, 2007).

engagement is on a continuum that states the two extremes, unaware of HIV infection and fully engaged in HIV care are the most definitive case of "Not in HIV Care," and "Engaged in HIV Care." The middle four statements give us a guide of the continuum than many others can be classified as such (Elred \& Malitz, 2007).

\section{Working Definition}

The term engagement is the amalgamation of the interwoven process of linkages to HIV care, retention is this care, and re-engagement in care if need be [19] [26]. Additionally, this engagement includes medication compliance and all medical appointment utilization. The inference of engagement is longitudinally based, and is focused on outpatient medical utilization of all medical, psychosocial, and other healthcare services while dealing with total body health, but the focus is on the HIV-infection.

\section{Defining Attributes}

Engagement is an attitude and manifestation of substance that leads one to believe that the HIV-infected patient is compliant with his or her HAART and adherent with other health care appointments and procedures. Adherence and compliance are related terms with each other and engagement. The aspect of compliance with medication regimen is crucial and is one of the defining attributes to engagement. Moreover, compliance with scheduled visits to healthcare providers is equally as important. Additional attributes to engagement is coping and social supports. To attain compliance and engagement in this paradigm, the patient needs to cope with his or her health status along with the exterior barriers to care [27]. Social supports are necessary from the time an inmate is about to be discharged from prison, being released from prison and the next 60-day after release [5]. Social supports are not only pivotal to the exterior barriers such as insurance red-tape, transportation barriers, employment barriers, etc., but also in the support of the mental health aspect of the patient with denial of the disease, self-control of undesired behaviors, self-acceptance, and dealing with the interpreted stigma of the disease. In fact, social support is considered an enabling factor of engagement [24] [28].

Successful coping and coping behaviors is paramount for a successful interlude into society for incarcerated males. Recidivism rates for incarcerated males are between $66 \%-75 \%$ and one of the most accurate harbingers for success in the community upon release are strong social support structures and their own knowledge about services for the disenfranchised in the community [29] [30]. Moreover, strong social support structures will include adept mental health services that promote teaching coping skills that may lead to healthy coping behaviors. To recap, the defining attributes are compliance, social supports, and coping.

\section{Antecedents}

The antecedents to engagement are HIV infection, desire to succeed, and readiness. As I made clear in the opening, the focus of engagement will be just the recently used terminology of the word that refers to the HIVinfected person and their disease process.

The individual obviously needs to be HIV-infected in order to possibly be engaged in treatment for the disease. The desire to succeed is imperative for the individual to not only succeed into the continuum of engagement, but also even to begin the process.

What I call desire to succeed may be discerned to include the term resilience. The Patient Self-Advocacy Scale was utilized in one study to describe the necessity to succeed in the intervention, along with other scale measures that describe whether patients will seek knowledge to which they do not fully understand [31]. A modicum of this desire to succeed must be present for engagement to be possible. This discussion may be inter- 
preted individually or under the guise of social supports, individuals may be swayed or instructed to be more willing to want to succeed.

A similar term for the desire to succeed is readiness. The construct of readiness is an interpretation by others of the individual who is HIV-infected person. Whereas the desire to succeed is truly internalized and may be measured by efforts put forth by the individual. Readiness would be considered a "diagnosis" of sorts that medical professionals, peers, and other support groups would give to the individual. These individuals will have had to attempt to ascertain services that would help their situations [31]. Such services would be case management, medical services, dental services, mental health treatments, housing, mental health treatments, etc. These measures can be measured by the HIV Cost and Services Utilization Tool [31]. This readiness has to be evident if engagement is to take place.

\section{Consequences}

The consequences to engagement are undetected viral load, increased CD4 count, optimal health in the individual, and improved community health, globally. All these descriptors have a positive inclination due to the multiple studies that propel this argument [5] [19] [22] [24] [26] [32]. Lack of individual engagement in the HIV-infection paradigm may lead to poorer health care outcomes, earlier recidivism, and death of the individual [26].

\section{Cases}

All of the four cases will be drawn from the following vignette: A 35-year-old African American male was released from a Level IV correctional facility in California four hours ago. We will call him James. James has been HIV-infected for three years and has been incarcerated the entire time upon knowing his positive status. He was given $\$ 75$ upon release from prison, along with two weeks' worth of ART medications, a bus voucher for two weeks, paperwork regarding his current medical condition, his next physician's visit, and information on how to contact his parole officer. His brother has just picked him upon outside the walls of the prison and asks James where he wants to go next.

\subsection{Model Case}

James tells his brother to take him to their mom's house. James and his mom talk many hours about his current condition and she states he can live there indefinitely as long as he follows the physician's orders and keeps his old lifestyle away from the house. Later that afternoon, James checks in with his parole officer who gives him a list of potential jobs that he states he will call tomorrow. James then goes down to the County Mental Health and Rehabilitation Center for assistance. The clerk at the center states they are all booked up for the next two days, but to come back in three business days. James sets up an appointment with a caseworker for the next available appointment. The next day, he goes to a series of job interviews for positions that specially request work from new parolees. From this, he is able to get a job. Later that week, James goes to the Center and with the help of the caseworker, fills out all the forms for the State Assistance program for his ART medication and verifies his first medical appointment with an HIV-specialist physician for next week. James purposely ignores his old "friends" (the ones he used to get high and have sex with) while spending time with his mother and brother at home every night of the week. The post-release RN calls to check on James, and he states everything is "a-ok." Because of his diligence and planning, James was able to ascertain employment, housing, continuous ART medication without lapse in coverage, State assistance for these medication, and his first physician visit.

\subsection{Borderline Case}

James tells his brother to take him to their mom's house. James and his talk many hours about his current condition and states he can live there indefinitely as long as he follows the physician's orders and keeps his old lifestyle away from the house. Later that afternoon, James checks in with his parole officer who gives him a list of potential jobs that he states he will call tomorrow. James then goes down to the County Mental Health and Rehabilitation Center for assistance. The clerk at the center states they are all booked up for the next two days, but to come back in three business days. James does not make an appointment and states he will be back "when he gets time." The next day, he goes to a series of job interviews for positions that specially request work from new 
parolees. From this, he is able to get a job. James purposely ignores his old "friends" (the ones he used to get high and have sex with) while spending time with his mother and brother at home every night of the week. The post-release RN calls to check on James, he states what he had accomplished but was unsure about his next physician visit or when his renew medication will be coming. The RN inquires about the referral to the County Mental Health and Rehabilitation Center for assistance. James states that they were busy and he was unable to complete this task. The RN sets up the appointment with the physician, but beseeches James to try again at the Center. The next morning the Center is able to accommodate James and he is set up with his paperwork. Because of his planning, and the help of the post-release RN, James was able to ascertain employment, housing, continuous ART medication without lapse in coverage (he came within one day of noncompliance), State assistance for these medication, and his first physician visit.

\subsection{Contrary Case}

James tells his brother to take him to his friend's house in the next county. James states that he was tired of being in prison for so long and wanted to "have some fun," because he "never got to do a damn thing while I was in there." James' brother reluctantly drops him off at the old dilapidated house that James used to party at years ago, one county over. Although James received copious instructions about the risks of illegal drug use with his diagnosis of HIV, he does anyways. Upon entering the house he has unprotected sex with one of his "exgirlfriends" while later in the evening they drink Vodka, smoke pot, and shoot up black tar heroin. A day later he takes a taxi to his mom's house where she summarily throws him out because he did not follow the rules of "non-intoxication," that they spoke about a week before he was released from prison. He loudly tells his mom to "go f*** herself" as he goes back to the party house from which he came. In the next three weeks, he parties like there is no tomorrow; having unprotected sex with women and men, sharing intravenous needles with strangers, drinking alcohol heavily and now starting to abuse benzodiazepines and other pill form narcotics. He currently has no money, out of his ART medication, and no follow up with any physician or ancillary provider. He has repeatedly ignored phone calls from his brother and his parole officer. Later that night he gets in a fight with a friend at the house and goes into the next room. There he sees some cocaine and does a couple of lines. After a few minutes he gets nervous that he is too jittery, so he shoots up more heroin, and ingests large doses of Valium. James goes to sleep 10 minutes later and never wakes up again.

\subsection{Related Case}

James tells his brother to take him to their mom's house. James and his mother come to an agreement about the living arrangements where James will do work around the house in lieu of paying rent each month. Over time, James acquires new friends that do not abuse drugs but they are on disability because of mental health issues. Though there is a new sense of drama with these new friends, they are somewhat supportive of James' attitude toward making a better life of himself, being HIV-infected and a former inmate. James continues to take his medication and go to his physician visits. He has sought out resources such as the pharmacy technician at the local Rite-Aid to help him understand the paperwork involved and co-pays if the State does not pay.

\section{Empirical Referents}

An empirical referent is a measure of an outcome. Walker \& Avant [8] proclaim that this section refers to recognizing or measuring the defining attributes of engagement, not necessary the concept of engagement. In my opinion this can be one in the same, ergo, we will be "measuring" compliance, social supports, and coping. This is much more abstract, so I will aim for recognition versus measurement. If we do look quantitatively, we can look at low viral load, high CD4 count, and lack of unexpected hospital or emergency room visits, as a quantitatively clear measurement of engagement or the attribute of engagement. Engagement is just not an activity, but a mindset that individuals must partake in to have optimal laboratory values, decreased exposure to other individuals in the community, and having the benefit of sustainability while being HIV-infected [17] [26] [27].

Compliance can easily be measured by a number of dichotomous results from a self-inventory from the client but that may not be entirely reliable [33]. Ergo, we must look at CD4 count and HIV RNA (viral load) to determine if one has been compliant with their medication regimen alone with primary care and ancillary care engagement [17] [26]. 
Social support can be broken down to formal and informal networks; the former being physicians and nurses, the latter being patient's families, friends, and peers [34]. Friends and peers provide social engagement that is necessarily for individuals to garner this social support [28]. This means that more social supports will lead to social engagement in the community (and also a reciprocal relationship) that also leads to less risky sexual behaviors. Social supports may be measured by Cohen [35] Interpersonal Support Evaluation List (ISEL), which measures perceived availability of potential social supports. ISEL is a Likert-type answering system, 40-item self-report that is broken into subgroups of belonging, self-esteem, appraisal, and tangible support. "Items were developed on theoretical grounds to cover the domains of social support resources that could potentially facilitate coping with stressful events” ([36], p. 80).

Upon reviewing instruments for measuring coping, there is a measure that focuses on gay men and their coping relationship to their HIV-infection. The Coping with Stress Self-Efficacy Scale (CSSES) is an eight-item Likert-type instruments that measures the person's perceived self-efficacy for coping [37].

\section{Discussion}

The term engagement is the amalgamation of interwoven processes of linkages to HIV care, retention is this care, and re-engagement in care if need be [19] [26]. The defining attributes and empirical referents of engagement are coping, social supports, and compliance. To fully engage in the process of the HIV-infection paradigm, one must fully subscribe to these tenants. The consequences to engagement are undetected viral load, optimal health, and improved community health. The lack of engagement leads to higher load virology, poor health, and poor community health projections [5] [17] [31] [32].

The engagement of IMIHIV to a HIV-infection treatment paradigm is not only crucial for public health, but also significant to nursing and research. The focus of nursing encompasses health, person, environment, and nursing, which we call the metaparadigm [38]. If we think of this on a very large scale, all four attributes keep balance with each other and are needed to work in concert for positive well-being of man, planet, and the universe [39]. Basically, positive interactions by nurses in the treatment of individuals bring a greater good to society. Moreover, the "discipline of nursing is concerned with the patterning of human health experiences within the context of the environment” ([38], p. 6). In essence, the discipline of nursing interacting in the environment provides the perfect context of research methodology to ensue. It is the responsibility of nurses to interact in this manner to balance out the health, person, and environment paradigm.

\section{Recommendations}

Obviously there is much room to grow in regard to the usage of the term engagement. As I have noted, it is relative a new term vis-à-vis the HIV-infection paradigm which deals specifically with adherence to medication, linkage to community resources, and compliance with medical and ancillary appointments. We have seen that increased engagement has led to lower viral loads, higher CD4 counts, and greater life expectancy of HIVinfected individuals, but most substantially in IMIHIV [23] [40]. There are potential questions that must be answered in the near future:

1) Can engagement be sustained without social supports?

2) We know that familial social supports are more successful than medical social supports [20]; can we introduce more familiar social supports into the prison system before release? Like a peer led program?

3) Can engagement in the HIV-infection paradigm transfer over to reduced recidivism for this population?

Finally, a stronger definition of engagement needs to be published that encompasses the linkage, medication compliance, and retention adherence to this paradigm.

\section{Conclusion}

It is crucial that IMIHIV and all HIV-infected individuals remain engaged in the HIV-infection paradigm that includes linkage to appropriate HIV care, compliance with HAART medications along with timely refills, adhering to all medical and ancillary visits prescribed, and retention in the HIV-infection paradigm. As I have stated, there is copious evidence to show that engagement in this process has shown decreased viral loads, increased CD4 counts, and decreased mortality. Moreover, as nurses, it is imperative for us to play a role in these endeavors as a vital link to a disenfranchised part of our community to the rest of the environment. 


\section{References}

[1] Belenko, S.R., Shedlin, M. and Chaple, M. (2005) HIV Risk Behaviors, Knowledge, and Prevention Service Experiences among African American and Other Offenders. Journal of Healthcare for the Poor and Underserved, 16, 108129. http://dx.doi.org/10.1353/hpu.2005.0075

[2] Binswanger, I.A., et al. (2011) From the Prison Door Right to the Sidewalk, Everything Went Downhill. A Qualitative Study of the Health Experiences of Recently Released Inmates. International Journal of Law and Psychiatry, 34, 249255. http://dx.doi.org/10.1016/j.ijlp.2011.07.002

[3] Springer, S.A., et al. (2011) Public Health Implications for Adequate Transitional Care for HIV-Infected Prisoners: Five Essential Components. Clinical Infectious Diseases, 53, 469-479. http://dx.doi.org/10.1093/cid/cir446

[4] Maruschak, L.M. (2009) HIV in Prisons, 2007-2008 (NCJ 213897). In: Justice, D.O., Ed., Bureau of Justice, Washington DC.

[5] Cavaleri, M.A., et al. (2010) Barriers to HIV Care: An Exploration of the Complexities That Influence Engagement in and Utilization of Treatment. Social Work in Health Care, 49, 934-945. http://dx.doi.org/10.1080/00981389.2010.514563

[6] Moore, R.D. (2011) Epidemiology of HIV Infection in the United States: Implications for Linkage to Care. Clinical Infectious Diseases, 52, S208-S213. http://dx.doi.org/10.1093/cid/ciq044

[7] Clements-Nolle, K., et al. (2008) Highly Active Antiretroviral Therapy Use and HIV Transmission Risk Behaviors among Individuals Who Are HIV Infected and Were Recently Released from Jail. American Journal of Public Health, 98, 661-666. http://dx.doi.org/10.2105/AJPH.2007.112656

[8] Walker, L.O. and Avant, K.C. (2011) Strategies for Theory Construction in Nursing. 5th Edition, Prentice Hall, New York.

[9] Tobias, C., et al. (2007) Making the Connection: The Importance of Engagement and Retention in HIV Medical Care. AIDS Patient Care STDS, 21, S3-S8. http://dx.doi.org/10.1089/apc.2007.9992

[10] (2005) Department of Health and Human Services. HIV Care.

[11] Prado, G., Pantin, H., Schwartz, S.J., Lupei, N.S. and Szapocznik, J. (2006) Predictors of Engagement and Retention into a Parent-Centered, Ecodevelopmental HIV Preventive Intervention for Hispanic Adolescents and Their Families. Journal of Pediatric Psychology, 31, 874-890. http://dx.doi.org/10.1093/jpepsy/jsj046

[12] Tobias, C.R., et al. (2007) Living with HIV but without Medical Care: Barriers to Engagement. AIDS Patient Care \& STDs, 21, 426-434. http://dx.doi.org/10.1089/apc.2006.0138

[13] Cabral, H.J., et al. (2007) Outreach Program Contacts: Do They Increase the Likelihood of Engagement and Retention in HIV Primary Care for Hard-to-Reach Patients? AIDS Patient Care \& STDs, 21, S59-S67. http://dx.doi.org/10.1089/apc.2007.9986

[14] Rumptz, M.H., et al. (2007) Factors Associated with Engaging Socially Marginalized HIV-Positive Persons in Primary Care. AIDS Patient Care \& STDs, 21, S30-S39. http://dx.doi.org/10.1089/apc.2007.9989

[15] Rajabiun, S., et al. (2007) “Getting Me Back on Track”: The Role of Outreach Interventions in Engaging and Retaining People Living with HIV/AIDS in Medical Care. AIDS Patient Care \& STDs, 21, S20-S29. http://dx.doi.org/10.1089/apc.2007.9990

[16] Basta, T., Shacham, E. and Reece, M. (2008) Psychological Distress and Engagement in HIV-Related Services among Individuals Seeking Mental Health Care. AIDS Care, 20, 969-976. http://dx.doi.org/10.1080/09540120701767240

[17] Dombrowski, J.C., Kent, J.B., Buskin, S.E., Stekler, J.D. and Golden, M.R. (2012) Population-Based Metrics for the Timing of HIV Diagnosis, Engagement in HIV Care, and Virologic Suppression. AIDS, 26, 77-86. http://dx.doi.org/10.1097/QAD.0b013e32834dcee9

[18] Wohl, A.R., et al. (2011) A Youth-Focused Case Management Intervention to Engage and Retain Young Gay Men of Color in HIV Care. AIDS Care, 23, 988-997. http://dx.doi.org/10.1080/09540121.2010.542125

[19] Mugavero, M.J., Norton, W.E. and Saag, M.S. (2011) Health Care System and Policy Factors Influencing Engagement in HIV Medical Care: Piecing Together the Fragments of a Fractured Health Care Delivery System. Clinical Infectious Diseases, 52, S238-S246. http://dx.doi.org/10.1093/cid/ciq048

[20] Mayer, K.H. (2011) Introduction: Linkage, Engagement, and Retention in HIV Care: Essential for Optimal Individualand Community-Level Outcomes in the Era of Highly Active Antiretroviral Therapy. Clinical Infectious Diseases, 52, S205-S207. http://dx.doi.org/10.1093/cid/ciq043

[21] Aberg, J.A., et al. (2009) Primary Care Guidelines for the Management of Persons Infected with Human Immunodeficiency Virus: 2009 Update by the HIV Medicine Association of the Infectious Diseases Society of America. Clinical Infectious Diseases, 49, 651-681. http://dx.doi.org/10.1086/605292

[22] Konkle-Parker, D.J., Amico, K.R. and Henderson, H.M. (2011) Barriers and Facilitators to Engagement in HIV Clini- 
cal Care in the Deep South: Results from Semi-Structured Patient Interviews. Journal of the Association of Nurses in AIDS Care, 22, 90-99. http://dx.doi.org/10.1016/j.jana.2010.06.002

[23] Mugavero, M.J., Davila, J.A., Nevin, C.R. and Giordano, T.P. (2010) From Access to Engagement: Measuring Retention in Outpatient HIV Clinical Care. AIDS Patient Care \& STDs, 24, 607-613. http://dx.doi.org/10.1089/apc.2010.0086

[24] George, S., Garth, B., Wohl, A.R., Galvan, F.H., Garland, W. and Myers, H.F. (2009) Sources and Types of Social Support That Influence Engagement in HIV Care among Latinos and African Americans. Journal of Health Care for the Poor \& Underserved, 20, 1012-1035. http://dx.doi.org/10.1353/hpu.0.0210

[25] National HIV/AIDS (2012) HIV Prevention.

[26] Mugavero, M.J., et al. (2012) Early Retention in HIV Care and Viral Load Suppression: Implications for a Test and Treat Approach to HIV Prevention. Journal of Acquired Immune Deficiency Syndromes: JAIDS, 59, 86-93. http://dx.doi.org/10.1097/QAI.0b013e318236f7d2

[27] Konkle-Parker, D. and Barnett, G. (2012) Keeping Patients in Care: A Critical Component in Controlling HIV. HIV Clinician, 24, 1-4.

[28] Fergus, S., Lewis, M.A., Darbes, L.A. and Kral, A.H. (2009) Social Support Moderates the Relationship between Gay Community Integration and Sexual Risk Behavior among Gay Male Couples. Health Education \& Behavior, 36, 846859. http://dx.doi.org/10.1177/1090198108319891

[29] Culbert, G.J. (2011) Understanding the Health Needs of Incarcerated Men Living with HIV/AIDS: A Primary Health Care Approach. Journal of the American Psychiatric Nurses Association, 17, 158-170. http://dx.doi.org/10.1177/1078390311401617

[30] Baillargeon, et al. (2010) Predictors of Reincarceration and Disease Progression among Released HIV-Infected Inmates. AIDS Patient Care \& STDs, 24, 389-394. http://dx.doi.org/10.1089/apc.2009.0303

[31] Bogart, L.M., Wagner, G.J., Mutchler, M.G., Risley, B.D., McDavitt, B.W., McKay, T. and Klein, D.J. (2012) Community HIV Treatment Advocacy Programs May Support Treatment Adherence. AIDS Education \& Prevention, 24, 1-14. http://dx.doi.org/10.1521/aeap.2012.24.1.1

[32] Gardner, E.M., McLees, M.P., Steiner, J.F., del Rio, C. and Burman, W.J. (2011) The Spectrum of Engagement in HIV Care and Its Relevance to Test-and-Treat Strategies for Prevention of HIV Infection. Clinical Infectious Diseases, 52, 793-800. http://dx.doi.org/10.1093/cid/ciq243

[33] Marks, G., et al. (2011) The Spectrum of Engagement in HIV Care: Do More than 19\% of HIV-Infected Persons in the US Have Undetectable Viral Load? Clinical Infectious Diseases, 53, 1168-1169.

[34] George, S., Garth, B., Wohl, A.R., Galvan, F.H., Garland, W. and Myers, H.F. (2009) Sources and Types of Social Support That Influence Engagement in HIV Care among Latinos and African Americans. Journal of Health Care for the Poor \& Underserved, 20, 1012-1035. http://dx.doi.org/10.1353/hpu.0.0210

[35] Cohen, F. and Lazarus, R.S. (1973) Active Coping Processes, Coping Dispositions, and Recovery from Surgery. Psychosomatic Medicine, 35, 375-389. http://dx.doi.org/10.1097/00006842-197309000-00002

[36] Chronister, J.A., Johnson, E.K. and Berven, N.L. (2006) Measuring Social Support in Rehabilitation. Disability \& Rehabilitation, 28, 75-84. http://dx.doi.org/10.1080/09638280500163695

[37] Colodro, H., Godoy-Izquierdo, D. and Godoy, J. (2010) Coping Self-Efficacy in a Community-Based Sample of Women and Men from the United Kingdom: The Impact of Sex and Health Status. Behavioral Medicine, 36, 12-23. http://dx.doi.org/10.1080/08964280903521362

[38] Fawcett, J., Watson, J., Neuman, B., Walker, P.H. and Fitzpatrick, J.J. (2001) On Nursing Theories and Evidence. Journal of Nursing Scholarship, 33, 115-119. http://dx.doi.org/10.1111/j.1547-5069.2001.00115.x

[39] Rogers, M. (1970) Theoretical Basis of Nursing. F.A.D. Company, New York.

[40] Whitten, L. (2011) HIV Treatment Interruption Is Pervasive after Release from Texas Prisons. Nida Notes, 23, 4-6. 